\section{MIRTAZAPINE - A MULTIFUNCTIONAL DRUG: LOW DOSE FOR AKATHISIA}

\section{To the Editor:}

CNS Spectrums should be commended for drawing the attention of clinicians and researchers to the concept of multifunctional drugs. ${ }^{1}$ Multifunctional drugs are agents with multiple therapeutic effects at different doses, depending upon their potency at diverse pharmacologic targets. ${ }^{2}$ Quetiapine, trazadone, and doxepine are examples of multifunctional drugs. ${ }^{1,3}$ Thus, quetiapine at high doses exerts dopamine $(\mathrm{D})_{2}$ and serotonin $(5-\mathrm{HT})_{2 \mathrm{~A}}$ receptor antagonism and is used as an antipsychotic and antimanic agent. In contrast, quetiapine like doxepine, at very low doses acts as a potent histamine $(\mathrm{H})$, receptor antagonist exhibiting robust hypnotic properties. Similarly, trazodone at low doses antagonizes $5-\mathrm{HT}_{2 \mathrm{~A}}, \mathrm{H}_{1}$, and $\alpha_{1}$-adrenergic receptors that account for its sedative and hypnotic therapeutic effects. Trazodone in doses 3-5 times higher exerts an additional inhibitory effect at the serotonin transporter and becomes an antidepressant. ${ }^{3}$

Mirtazapine is a widely used antidepressant and anti-anxiety medication. In therapeutic doses (range 30-90 mg/day) mirtazapine is characterized by a potent pre-synaptic $\alpha_{2}$-adrenergic receptor blockade which accounts for its antidepressant activity. Low-dose mirtazapine predominantly antagonizes $5-\mathrm{HT}_{2 \mathrm{~A} / 2 \mathrm{C}}$ and $\mathrm{H}_{1}$ postsynaptic receptors. The preponderance of the $5-\mathrm{HT}_{2 \mathrm{~A}}$ receptor antagonism over $\mathrm{D}_{2}$ receptor blockade was put forward as a putative explanation for the low propensity of atypical antipsychotic agents to induce extrapyramidal side effects (eg, akathisia, parkinsonism, acute dystonia). ${ }^{4}$ Owing to its marked $5-\mathrm{HT}_{2 \mathrm{~A}}$ antagonistic properties, the addition of low-dose mirtazapine to typical antipsychotics that exert predominant $D_{2}$ receptor antagonism, was suggested to test this hypothesis. When given $\mathrm{OD}$, low-dose mirtazapine $(15 \mathrm{mg})$ revealed a robust antiakathisia effect comparable to that of propranolol, the "gold standard" for akathisia, mirtazapine's $\mathrm{H}_{1}, \alpha_{2}$ and $5-\mathrm{HT}_{3}$ antagonistic effects are unlikely to play a role, since antihistamines, $\alpha_{2}$ and $5-\mathrm{HT}_{3}$ antagonists are apparently ineffective in the treatment of akathisia. ${ }^{6}$ Notably, mirtazapine administered in higher doses ( $\geq 30 \mathrm{mg} /$ day) may induce akathisia in susceptible individuals, putatively due to stimulation of adrenergic neurotransmission via $\alpha_{2}$ auto-receptor blockade. It seems that mirtazapine is unique in its dose-related bi-directional effect on akathisia: low doses have an anti- akathisia effect while higher doses may provoke akathisia.

The antidepressants mianserin (a structural analogue of mirtazapine) and trazodone, as well as cyproheptadine (an anti-allergy agent), that share marked 5 $\mathrm{HT}_{2 \mathrm{~A}}$ antagonism at low doses, revealed anti-akathisia properties in antipsychotictreated schizophrenia patients. ${ }^{8}$ Notably, the effect of low-dose mirtazapine and the related compounds on antipsychoticinduced parkinsonism did not differ significantly from that of placebo, supporting the hypothesis regarding the distinct pharmacological mechanisms underlying antipsychotic-induced extrapyramidal adverse effects. Overall, the revealed robust effect of low-dose mirtazapine on antipsychotic-induced akathisia, in addition to its beneficial safety and tolerability profile, encourage modification of treatment guidelines for acute akathisia, by recommending low-dose mirtazapine along with propranolol as first-line anti-akathisia treatments.,9

Mirtazapine seems to be an additional example of a multifunctional agent used as an efficacious antidepressant in the approved dose range, and an effective antiakathisia compound at a lower dose range.

Sincerely,

Michael Poyurovsky, MD

Ronit Weizman, MD

Abraham Weizman, MD

\section{REFERENCES}

1. Stahl SM. Multifunctional Drugs. A Novel Concept for Psychopharmacology. CNS Spectr. 2009;14(2):71-73.

2. Van der Schyf CJ, Youdim MB. Multifunctional drugs as neurotherapeutics. Neurotherapeutics. 2009;6(1):1-3.

3. Stahl SM. Mechanism of action of trazodone: a multifunctional drug. CNS Spectr. 2009:14(10):536-346.

4. Meltzer HY, Matsubara S, Lee JC. Classification of typical and atypical antipsychotic drugs on the basis of dopamine D-1, D-2 and serotonin-2 pKi values. $J$ Pharmacol Exp Ther. 1989;251(1):238-246.

5. Poyurovsky M, Pashinian A, Weizman R, Fuchs C Weizman A. Low-dose mirtazapine: a new option in the treatment of antipsychotic-induced akathisia. A randomized, double-blind, placebo- and propranolol-controlled trial. Biol Psychiatry. 2006;59(11):1071-1077.

6. Poyurovsky M, Weizman A Lack of efficacy of the 5-HT3 receptor antagonist granisetron in the treatment of acute neuroleptic-induced akathisia. Int Clin Psychopharmacol. 1999;14(6):357-360.

7. Gulsun M, Doruk A. Mirtazapine-induced akathisia. $J$ Clin Psychopharmacol. 2008; 28(4):467.

8. Stryjer R, Strous RD, Bar F, et al. Treatment of neurolepticinduced akathisia with the 5-HT2A antagonist trazodone. Clin Neuropharmacol. 2003:26(3):137-141.

9. Hieber R, Dellenbaugh T, Nelson LA. Role of mirtazapine in the treatment of antipsychotic-induced akathisia Ann Pharmacother. 2008:42(6):841-846.

Dr. Poyurovsky is associate professor and department head in the Department of Acute Admissions at the Tirat Carmel Mental Health Center, Tirat Carmel and Rappaort Faculty of Medicine, Technion, Israel Institute of Technology in Haifa, Israel. Dr. Weizman is professor at the Tel Aviv Community Mental Health Center; Sackler Faculty of Medicine at Tel-Aviv University. Dr. Weizman is professor, at the Geha Psychiatric Hospital, Research Unit; Felsenstein Medical Research Center; Sackler Faculty of Medicine at Tel-Aviv University.

Faculty Disclosures: The authors report no affiliation with or financial interest in any organization that might pose a conflict of interest.

Submitted for publication: January 26, 2010; Accepted for publication: April 19, 2010. First published online: February 1, 2011

Please direct all correspondence to: Michael Poyurovsky, MD, Tirat Carmel Mental Health Center, POB 9, Tirat MD, Tirat Carmel Mental Healh Center, POB 9, Tirat Carmel 30200, Israel; Tel: +972-4-8559349, Fax
+972-4-8559330; E-mail: poyurovs@tx.technion.ac.il 